\title{
Presente y Futuro de la Sociedad Chilena de Enfermedades Respiratorias
}

Es para mí un gran honor asumir la presidencia de la Sociedad Chilena de Enfermedades Respiratorias (SER), la cual recientemente ha cumplido 75 años de trayectoria. Deseo en primer lugar agradecer a todos quienes hace dos años depositaron su confianza en mi persona. Asumo esta tarea con humildad, pero a la vez con fortaleza y el deseo de engrandecer aún más esta Sociedad Científica que nos acoge, y así enfrentar de la mejor forma los grandes desafios del futuro.

Nuestra Sociedad Científica se encuentra actualmente constituida por 500 socios titulares o asociados, correspondiendo a 267 médicos de adultos, 143 pediatras y otros 90 profesionales del área de la salud (enfermería, kinesiología y tecnología médica). Es importante destacar que el $80 \%$ de los médicos especialistas cuenta con el reconocimiento de la especialidad por CONACEM.

El objetivo básico de la Sociedad es velar porque la atención preventiva y curativa de las enfermedades respiratorias en nuestro país, sea del más alto nivel posible. Para lograr estos objetivos existen diversos mecanismos:

1.- Fomentar e incentivar la permanente actualización y perfeccionamiento de los especialistas y clínicos generales a través de Guías Clínicas, Congresos, Jornadas, Cursos, Becas de Estudios, Estadías de Perfeccionamiento, etc. Mantener una activa participación en la revisión y confección de guías clínicas de enfermedades respiratorias de adultos y de pediatría, lo cual ya hemos logrado con la Comisión de Neumonías, Asma Bronquial y Enfermedad Pulmonar Obstructiva Crónica.

Apoyar y mantener nuestras reuniones científicas, que son instancias fundamentales para el intercambio de conocimientos, y más aún de fortalecimiento de nuestras amistades: Jornadas de Otoño, Jornadas de Invierno y Congreso Anual de la Especialidad.

Para lograr este objetivo es fundamental la participación de todos y cada uno de sus socios. Toda Sociedad es el reflejo del compromiso de sus integrantes, por lo que se debe incentivar en igual forma la participación de especialistas de adultos, pediatras y cirujanos de la especialidad. Además, la Sociedad se enriquece con el aporte de especialistas de otras áreas o disciplinas durante sus actividades científicas, por lo que es necesario incentivar la participación de neumólogos de adultos y pediatría, intensivistas, infectólogos, microbiólogos, cirujanos, epidemiólogos, investigadores básicos, etc.

Durante las actividades científicas es importante incentivar la participación de los socios de provincia, y en este sentido quiero aprovechar de destacar el importante rol que han desempeñado los colegas de provincia en el éxito de las actividades de la SER, en especial en los Cursos y Congresos anuales que se realizan fuera de Santiago.

Se pretende apoyar a los socios con: a) Becas de Perfeccionamiento en Centros Nacionales y Extranjeros. Para lograr este objetivo se deben acreditar los centros nacionales capacitados para impartir docencia en áreas específicas de la especialidad; b) Becas de Asistencia a Cursos de Perfeccionamiento o Cursos de Post-grado nacionales y en el extranjero.

Otro aspecto importante de destacar, ha sido el interés del Directorio de facilitar a los socios el acceso a la literatura médica de vanguardia, con este objetivo se ha establecido un acceso a "MD Consult" para acceder a la literatura de la especialidad, lo que se puede realizar a través de la página web de la Sociedad, el único requisito es ser miembro de la Sociedad Chilena de Enfermedades Respiratorias y solicitar su clave de acceso.

Finalmente, un aspecto importante y que debemos retomar son los Cursos de Educación Continua que han sido un gran aporte para la formación de post-grado de especialistas en enfermedades respiratorias del adulto y del niño.

\section{2.- Fomento de la investigación a través de apoyo técnico y financiero.}

Promover el desarrollo científico dentro de la Sociedad con recursos económicos y humanos. Hemos apoyado proyectos de investigación y queremos potenciarlos aún más, en el área básica, clínica y epidemiológica. De gran importancia en este sentido ha sido el llamado a concurso que hemos realizado para Proyectos Multicéntricos, que tuvo una excelente acogida entre los socios con presentación de proyectos de alto nivel científico.

3.- Constituirse en un referente preferencial para las autoridades gubernamentales.

Lograr que la SER llegue a ser un referente técnico ante la Comunidad, la Sociedad, y la autoridad 
competente en temas de la especialidad, y en especial en aspectos contingentes como la ley antitabaco, el plan Auge y el programa de control de la contaminación ambiental intra y extradomiciliaria.

Para lograr este objetivo es necesario mejorar la comunicación con el Ministerio de Salud y organismos competentes. La Comisión Antitabaco de la SER, bajo la dirección de la Dra. Marisol Acuña, con la participación activa de otras Sociedades Científicas, como la Sociedad Chilena de Oncología, Cardiología y Medicina Intensiva, han tenido un rol importante en el logro de la aprobación del Convenio Marco para el Control del Tabaco y actualmente esperamos poder continuar asesorando efectivamente, de modo de obtener la aprobación en el Congreso Nacional de la ley antitabaco.

La SER debería organizar y promover campañas de prevención de las enfermedades respiratorias a nivel nacional, a través de los organismos competentes, por ejemplo, la Campaña de Vacunación contra la Influenza anual, la prevención de las enfermedades respiratorias agudas del niño durante los meses de invierno, entre otras.

4.- Coordinación e integración con las Sociedades Científicas afines nacionales y extranjeras.

Parece necesario en una época de globalización, estrechar lazos con las Sociedades Científicas de Enfermedades Respiratorias de otros países, y en especial con los países hermanos de Latinoamérica, para lo cual se deberá revitalizar la comunicación con Sociedades Científicas Internacionales como ALAT y la Sociedad Española de Neumología. Además, nuestro Congreso anual debería trascender nuestras fronteras, lo cual puede ser factible al emplear la tecnología moderna existente y la comunicación fluida que se puede lograr con la web.

\section{5.- Mantener relaciones fluidas y transparentes con los laboratorios e instituciones patrocinadoras} de nuestras actividades.

Mantener un vínculo de beneficio mutuo con la industria farmacéutica y las empresas del área médica que nos apoyan, ya que con su estrecha colaboración contribuyen al éxito de nuestras actividades, lo que beneficia a nuestros socios y a nuestros pacientes, quienes son nuestro fin último. El mantener una relación armónica con estas instituciones es un deber que hemos asumido y nos permite asegurar la permanencia de nuestra Sociedad.

\section{Responsabilidad de los socios}

Para ello deseo contar con la colaboración de cada uno de nuestros socios. La SER es una sociedad compuesta y liderada por socios, sus actividades son desarrolladas y dirigidas hacia sus socios, de modo que sin la participación de éstos la directiva de la Sociedad no sería un fiel representante de sus intereses. Ninguno de nosotros se puede atribuir experiencia en todas las áreas de la especialidad, es por esta razón que les pedimos a todos los socios su participación activa en las distintas comisiones de trabajo de la SER, en especial a los miembros más jóvenes.

La organización y planificación de todas estas actividades se optimiza en la medida que los socios tengan una máxima participación en ellas de acuerdo a su disponibilidad de tiempo, incorporándose a las comisiones de su interés, contestando las encuestas de la Sociedad, manteniendo contacto a través de la página web y con la Revista Chilena de Enfermedades Respiratorias. Esta directiva se compromete a mantener información abierta, fluida y oportuna, a través de los distintos medios de comunicación disponibles (página web, boletines, revista), sobre las actividades desarrolladas por las distintas comisiones y el número de cupos de cada una de ellas (las normas para la postulación se encuentran disponibles en la página web y secretaría de la sociedad), de modo que todos los socios puedan participar.

Para lograr estos objetivos estoy convencido que es fundamental que la Sociedad se sustente sobre bases sólidas, que trasciendan el período de un Directorio. Para ello es necesario promover el trabajo de las Comisiones de Adultos y Pediatría. Que deberían ser las que definan el camino, el prestigio y trascendencia de la SER. Con este propósito hemos incentivado la participación activa y creativa de los socios en las distintas comisiones, lo que debería traducirse en el desarrollo de las distintas áreas de la especialidad. Esto se fomentará otorgándole un espacio a las comisiones en las Jornadas de Otoño e Invierno y durante el congreso anual para realizar actividades específicas.

La Revista Chilena de Enfermedades Respiratorias circula en forma regular desde hace más de veinte años, y desde 2002 se encuentra incluida en la base SciELO (Scientific Electronic Library Online), siendo el órgano oficial de difusión de nuestro quehacer científico, y debería reflejar la productividad nacional de nuestra especialidad. Actualmente tenemos cuatro números anuales, nuestro anhelo es aumentar la producción a cinco o seis números anuales y lograr indexarla en el futuro cercano en la base de datos internacional Index Medicus-MEDLINE. 